\title{
Studies of the Anti Oxidant Status in Subjects With Altered Metabolism in Niger Delta Region of Nigeria
}

\author{
${ }^{1}$ Ezeiruaku, F. C. And ${ }^{2}$ Eze, E.M. \\ ${ }^{I}$ Department Of Medical Laboratory Science, Faculty Of Basic Medical Sciences, College Of Health Sciences, \\ Niger Delta University, Bayelsa State, Nigeria. \\ ${ }^{2}$ Department Of Medical Laboratory Science, Faculty Of Science, Rivers State University Of Science And \\ Technology, Nkpolu, Portharcourt, Nigeria.
}

\begin{abstract}
Altered metabolism is associated with several disease states with abnormal chemical reactions in the body. This leads to oxidative stress which is a result of imbalance between the generation of reactive oxygen species and the antioxidant defence system. Damage to this system has been provided to play a role in various health disorders. This study evaluated and compared the antioxidant status of subjects with sickle cell disease, chronic diabetes mellitus and hypertension in the Niger Delta region of Nigeria. This is with a view to determine the long time complications of these disorders on the antioxidant compounds, vitamins $A, C, E$ and the enzymes, superoxide dismutase, glutathione peroxidase and catalase. A total of 230 subjects were used for this study, this comprised of 50 sickle cell disease, 60 chronic diabetes mellitus, 60 chronic hypertensive and 60 apparently healthy control subjects with an average age of $40.15 \pm 21.92$ years. The enzyme linked immunosorbent assay (ELISA) method was used for the estimation of these antioxidant compounds. The result showed a significant decrease $(P<0.05)$ of these antioxidant compounds in plasma of the subjects with these disorders with respect to the normal control subjects. The depletion of the antioxidant compounds is in the order $S S D>D M>H T N$ subjects. Statistical analysis did not show any significant difference $(P>0.05)$ in the results obtained for the three disease states. The depletion has been attributed to oxidative stress associated with the sickling phenomenon in SSD subjects, chronic exposure to hyperglycaemia and insulin resistance in DM subjects and inactivation of the antioxidant compounds as a result of continuous exposure to hydrogen peroxide, hydrogen peroxynitrite and other free radicals in hypertensive subjects. The result of this study implicated an increased oxidative stress in the altered metabolic diseases with a decreased antioxidant vitamins and enzymes with a positive correlation.
\end{abstract}

Keywords: Antioxidant; Metabolism; Oxidative stress; Sickle cell anaemia; Diabetes mellitus; Hypertension.

\section{Introduction}

A paradox in metabolism is that, while the vast majority of complex life on earth requires oxygen for its existence, oxygen is a highly reactive molecule that damages living organisms by producing reactive oxygen species (Davies, 1995). Consequently, organism contains a complex network of antioxidant metabolites and enzymes that work together to prevent oxidative damage to cellular components like DNA, proteins and lipids (Sies, 1997).

Altered metabolism as seen in certain pathological dysfunctions is associated with several disease states with abnormal chemical reactions in the body. This leads to oxidative stress which is a result of imbalance between the generation of reactive oxygen species and the antioxidant defence system (Sinha and Dabla, 2015). Oxidative stress cause damage to cell structure and cell function by overly reactive oxygen containing molecules and chronic excessive inflammation. This oxidative stress play a significant role in many human diseases that also includes cancer (Lenaz, 2001), (Ezeiruaku and Udenwoke, 2016). Antioxidants terminate these chain reactions by removing free radical intermediate and inhibit the oxidation reactions (West, 2000). Oxidative stress, as has been hypothesized is a key player in the pathogenesis of several diseases that includes hypertension (Rodrigo et al., 2011), diabetes mellitus (Beynes and Thorpe, 1996) and sickle cell anaemia (Nur et al., 2011).

Hypertension (HTN) is a chronic medical condition that is rarely accompanied by symptoms. It is usually identified through screening or when the patient is seeking for an unrelated problem. Hypertension is a major risk factor for myocardial infarction, heart failures, stroke, peripheral arterial disease, aortic aneurysm and is a cause of chronic kidney disease (Chobanian et al., 2003; Azar et al., 2014). The relationship between hypertension, oxidative stress and antioxidants is complex and inadequately understood. Oxidative stress may play a role in the pathophysiology of hypertension. Human and animal studies has demonstrated that HTN is accompanied by increase in oxidative stress (Mujahid et al., 2011) and its postulated that hypertension may develop as a result of increased reactive oxygen species (Oparil et al., 2003). 
Sickle cell anaemia (SCA) is an inherited blood disorder due to homozygous presence of haemoglobin $\mathrm{S}$ (HbSS) in the haemoglobin molecule (Lamia et al., 20015). It is the most common genetic disorder in persons of African Origin (Huisman, 1981) and its associated with several complications, including oxidative stress and generation of free radicals (Yoshikawa et al., 2000). There has been a growing body of evidence suggesting that an increase in oxidative stress and abnormal oxidants/antioxidants balance are implicated in the pathophysiology of several dysfunction observed in sickle cell anaemia (Nur et al., 2011) resulting in various haematological and biochemical changes (Odievre et al., 2011), that includes production of reactive oxygen species (ROS) like superoxide radicals, hydrogen peroxide, hydroxyl radicals and nitric oxide.

The complications of Diabetes Mellitus, a group of metabolic disorder of carbohydrate metabolism in which glucose is underutilized, producing hyperglycaemia are far less common and less severe in people who have well controlled blood levels. In chronic or uncontrolled situations, insufficient level of antioxidants or inhibition of the antioxidant enzymes cause oxidative stress which occur due to over increase in production of free radicals or impaired compensatory response to antioxidant defense system (Gingliano et al., 1996).

Antioxidants has been postulated to reverse many of the effect of hyperglycemias (Manisha, 1999), hypertension and cardiovascular diseases (Schiffrin, 2010) and even in sickle cell anaemia (Wright et al., 2014). In general antioxidant system either prevent the oxygen reactive species from being formed or they remove them before they can damage vital components of the cell. Epidemiological evidence suggests that antioxidants including vitamins C, E alpha and $\beta$-carotene may be therapeutic. However, according to Schiffrin, 2010, intervention trials of antioxidants have provided mixed results.

Deficiency of these enzymes and vitamins may thus increase susceptibility to the diseases and its attendant complications (Coyne, 2005). Antioxidants capacity is an important cause of tissue injury, particularly in patient with elevated oxidative stress (Walter et al., 2006). This study focused on the state of the antioxidant defense system in patients with altered metabolism by estimating and comparing the level of the antioxidant enzymes; extracellular superoxide dismutase (EC SOD), glutathione peroxidase (GPX), catalase ( CAT) and antioxidant compounds, vitamin A, C, E in these metabolic disorders in the Niger Delta region of Nigeria.

\section{Study Area}

The samples for this study were collected from subjects in Bayelsa, and Rivers State, Niger Delta region of Nigeria. Samples were collected specifically from sickle cell centres, Federal Medical centre in Yanegoa, Niger Delta University teaching hospital, Okolobiri and the University of Port Harcourt Teaching Hospital, Port Harcourt.

\section{Study Subjects}

A total of 230 participants constituted the subjects for the study. They included 50 sickle cell patients (23 males, 27 females) in a steady state, 60 chronic Diabetic mellitus patients (30 males, 30 females) that have suffered the disease for above 5 years, 60 chronic hypertensive patients (30 males, 30 females) and 60 apparently healthy subjects (30 males, 30 females). All the subjects were in the age range of 18 and above years, with an average age of $40.15 \pm 21.92$ years. The subjects with varying levels of clinical complications were excluded from the study. Specifically were sickle cell anaemia patients with acute febrile illness, vaso occlusion cases and patients who have had a recent blood transfusion. The test diabetic subjects were those whose glycated haemoglobin (HbAic) and fasting blood glucose (FBG) values were $>7.0 \%$ and $>6.0 \mathrm{mMol} / 1$ respectively and the control subjects were those whose HbAic and FBG values were $<7.0 \%$ and $<6.0 \mathrm{mMol} / 1$ respectively (WHO, 2011). The test hypertensive subjects were those with a blood pressure above $140 / 80 \mathrm{mmHg}$ (systolic pressure $>140 \mathrm{mmHg}$ and diastolic pressure $>80 \mathrm{mmHg}$ ). Informed consent was obtained from all subjects and a structured interviewer administered questionnaire was used to collect data such as age, gender, previous complications, current treatment regime and duration of illness.

\section{Methods}

The haemoglobin electrophoretic pattern of each SCD Subject was confirmed using haemoglobin electrophoresis. Fasting plasma glucose (FPG) was estimated quantitatively using the Glucose Oxidase method as modified by Randox Laboratories Limited (United Kingdom). HbAic levels were estimated quantitatively using immunoassay method as described by Chek diagnostics (USA). The enzyme linked immunosorbent assay (ELISA) method was used to estimate the antioxidant enzymes (superoxide dismutase, Glutathione peroxidase and Catalase) and the vitamins A, C, and E. The Elabscience Biotechnology co Ltd (ELISA) kit was specifically used for the study. The components of the ELISA kit used were specifically designed to analyse the antioxidant enzymes and the vitamins. It applies to in-vitro quantitative determination of the enzyme and vitamin concentrations in plasma (Uotila et al., 1981; Peter et al., 2001). 


\section{Sample collection}

The study subjects (diabetic and non diabetic controls) were properly instructed to fast for about 10 to 14 hours before coming for sample collection. About ten millilitres $(10 \mathrm{ml})$ of venous blood was obtained from the subjects. This was distributed into the various anticoagulant tubes (EDTA, Fluoride Oxalate and Lithium heparin) for haemoglobin electrophoresis, fasting blood glucose and the various enzyme and vitamin assays. The sample in the lithium heparin tubes were separated by centrifugation at 3,000rpm for 10 minutes at room temperature and plasma used for the various enzyme and vitamin estimations. The essence and details of the study were explained to the subjects and verbal informed consent was obtained from them after approval from the management of the hospitals and centres through the ethical committee.

\section{Statistical Analysis}

The data were expressed as mean \pm standard deviation. The paired-test (test of significance) was done using the student's t-test to compare the groups. Differences were considered significant at $\mathrm{P}<0.05(95 \%$ confidence level). Correlation between the groups studied was tested using the regression analysis and analysis of variance (ANOVA). The results were considered statistically significant at 95\% confidence level $(\mathrm{P}<0.05)$.

\section{Results}

The result of this study on the antioxidants level of the enzymes and vitamins are as presented in the tables below. It showed a significant decrease $(\mathrm{P}<0.05)$ in the antioxidant parameters in sickle cell disease, diabetic mellitus and hypertensive subjects with respect to the non sickling, non diabetic, normotensive control subjects.

Table 1: Mean + S.D results for the various antioxidant compounds in the three disease states.

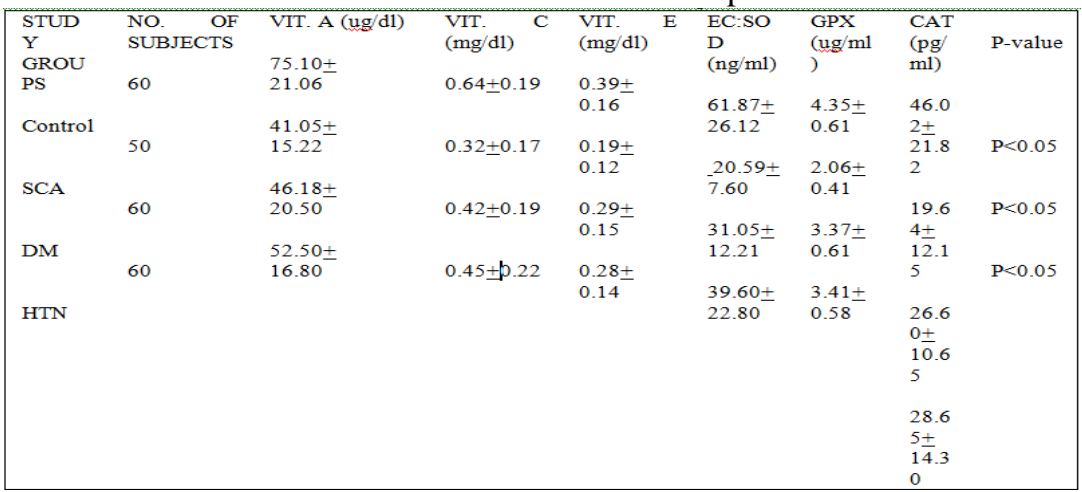

SCA = Sickle cell anaemia $; \mathrm{DM}=$ Diabetes mellitus $; \mathrm{HTN}=$ Hypertension

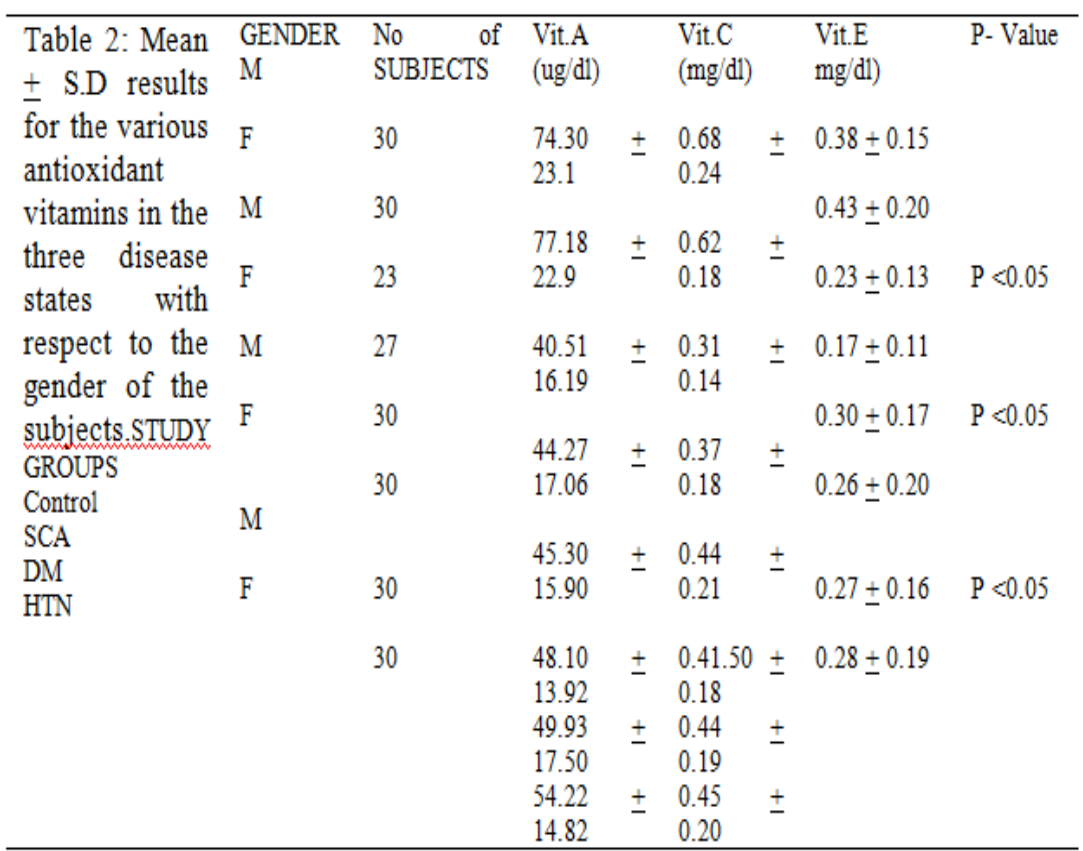

SCA = Sickle cell anaemia; DM = Diabetes mellitus; HTN = Hypertension 
Table 3: Mean \pm S.D results for the various antioxidant enzymes in the three disease states with respect to the gender of the subjects.

\begin{tabular}{|c|c|c|c|c|c|c|c|}
\hline \begin{tabular}{|l} 
STUDY \\
UPS
\end{tabular} & GENDER & $\begin{array}{c}\text { NO } \\
\text { [ECTS }\end{array}$ & $\overline{\mathrm{OF}}$ & $\begin{array}{l}\text { EC:SOD } \\
\text { (ng/ml) }\end{array}$ & $\begin{array}{l}\text { GPX } \\
\text { (ug/ml) }\end{array}$ & $\begin{array}{l}\text { CAT } \\
(\mathrm{pg} / \mathrm{ml})\end{array}$ & P-VALUE \\
\hline CONTROL & $\begin{array}{l}\mathbf{M} \\
\mathbf{F}\end{array}$ & $\begin{array}{l}30 \\
30\end{array}$ & & $\begin{array}{l}60.90 \pm 24.92 \\
63.47 \pm 25.84\end{array}$ & $\begin{array}{l}3.98 \pm 0.55 \\
4.62 \pm 0.67\end{array}$ & $\begin{array}{l}52.25 \pm 19.59 \\
45.87 \pm 20.95\end{array}$ & \\
\hline SCA & $\begin{array}{l}\mathbf{M} \\
\mathbf{F}\end{array}$ & $\begin{array}{l}23 \\
27\end{array}$ & & $\begin{array}{l}17.94 \pm 5.90 \\
22.75 \pm 7.28\end{array}$ & $\begin{array}{l}1.95 \pm 0.57 \\
2.27 \pm 0.46\end{array}$ & $\begin{array}{l}20.14 \pm 10.60 \\
19.05 \pm 11.82\end{array}$ & $P<0.05$ \\
\hline DM & $\begin{array}{l}\mathbf{M} \\
\mathbf{F}\end{array}$ & $\begin{array}{l}30 \\
30\end{array}$ & & $\begin{array}{l}28.28 \pm 15.31 \\
33.02 \pm 12.90\end{array}$ & $\begin{array}{l}3.67 \pm 0.72 \\
3.29 \pm 0.83\end{array}$ & $\begin{array}{l}25.60+9.46 \\
26.99 \pm 11.05\end{array}$ & $P<0.05$ \\
\hline HTN & $\begin{array}{l}\mathbf{M} \\
\mathbf{F}\end{array}$ & $\begin{array}{l}30 \\
30\end{array}$ & & $\begin{array}{l}38.15 \pm 20.50 \\
43.26 \pm 21.18\end{array}$ & $\begin{array}{l}3.30 \pm 0.52 \\
3.71 \pm 0.48\end{array}$ & $\begin{array}{l}27.94 \pm 13.89 \\
30.95 \pm 15.10\end{array}$ & $P<0.05$ \\
\hline
\end{tabular}

SCA $=$ Sickle cell anaemia; DM = Diabetes mellitus; HTN = Hypertension

Table 4: Pearson's correlation analysis of the relationships between the antioxidant enzymes level and the selected antioxidant vitamins in sickle cell anaemia and the control group.

Antioxidant compounds

\begin{tabular}{|l|l|l|l|}
\hline Vitamins & SOD & GPX & CAT \\
\hline Vitamin A & $0.197^{*}$ & $0.258^{*}$ & $0.307^{*}$ \\
\hline Vitamin C & $0.211^{*}$ & $0.297^{*}$ & $0.324^{*}$ \\
\hline Vitamin E & $0.247^{*}$ & $0.314^{*}$ & $0.379^{*}$ \\
\hline
\end{tabular}

SCA Patients $(n=50)$ control $(n=600$

Values in table are person's correlation coefficient (r)

$* \mathrm{P}<0.05$ indicates positive correlation

$\mathrm{SOD}=$ Superoxide dismutase

GPX= Glutathione peroxidise

$\mathrm{CAT}=$ Catalase

Table 5: Pearson's correlation analysis of the relationship between the antioxidant enzymes level and the selected antioxidant vitamins in diabetic mellitus and control group.

Antioxidant Compounds

\begin{tabular}{|l|l|l|l|}
\multicolumn{1}{l}{ r-value } \\
\begin{tabular}{|l|l|l|l|}
\hline Vitamins & SOD & GPX & CAT \\
\hline Vitamin A & $0.113^{*}$ & $0.194^{*}$ & $0.206^{*}$ \\
\hline Vitamin C & $0.146^{*}$ & $0.202^{*}$ & $0.199^{*}$ \\
\hline Vitamin E & $0.173^{*}$ & $0.231^{*}$ & $0.237^{*}$ \\
\hline
\end{tabular}
\end{tabular}

Diabetes mellitus patients $(n=60)$ control $(n=60)$

Values in table are Pearson's correlation coefficient (r)

$* \mathrm{P}<0.05$ indicate positive correlation

$\mathrm{SOD}=$ Superoxide dismutase

GPX= Glutathione peroxidise

$\mathrm{CAT}=$ Catalase

Table 6: Pearson's correlation analysis of the relationship between the antioxidant enzymes level and the selected antioxidant vitamins in hypertensive subjects and the control group.

Antioxidant compound r-value

\begin{tabular}{|l|l|l|l|}
\hline Vitamins & SOD & GPX & CAT \\
\hline Vitamin A & $0.097^{*}$ & $0.123^{*}$ & $0.109^{*}$ \\
\hline Vitamin C & $0.103^{*}$ & $0.116^{*}$ & $0.089^{*}$ \\
\hline Vitamin E & 0.119 & $0.139^{*}$ & $0.191^{*}$ \\
\hline
\end{tabular}

Hypertensive patients $(n=60)$ control $(n=60)$

Values in tables are Pearson's correlation coefficient (r)

$* \mathrm{P}<0.05$ indicate positive correlation

$\mathrm{SOD}=$ Superoxide dismutase

GPX $=$ Glutathione peroxidise

$\mathrm{CAT}=$ Catalase 


\section{Discussion}

Aerobic metabolism is always accompanied by the production of reactive oxygen species. This means, all aerobic organisms posses some sort of antioxidant defence with enzymatic and non-enzymatic constituents (Sies, 1995). The quantity and quality of the reactive species is determined by metabolic pathways within the organism, influenced by exogenous factors such as radiation, food, stress etc (Erika et al., 1999). The effects of these free radicals are therefore recognised in several metabolic disorders. This study compared the levels of the antioxidant enzymes; EC:SOD, GPX, and CAT and the vitamins A, C, and E in these altered metabolism and determined the correlation between the enzymes level and the vitamin in the three disease status. The result showed a significance $(\mathrm{P}<0.05)$ reduction in the antioxidant enzymes and vitamins (table 1$)$ with respect to the control (non sickling, non diabetic and non hypertensive) group. In the three disease states studied, variables existed in the order SCA >DM $>$ HTN subjects. Statistical analysis did not show any significant difference $(\mathrm{P}>0.05)$ between the results obtained for the different disease state. From the results, there was no statistical difference in the levels obtained for the gender groups (table 2 and 3). The reduction in the level of these antioxidant enzymes in relation to the antioxidant vitamin studied showed a positive correlation at $95 \%$ confidence level $(\mathrm{P}<0.05)$. This is as a result of both the antioxidant enzymes and vitamins been significantly $(\mathrm{P}<0.05)$ reduced in the different disease states (table 4-6). The result of this study is comparable to the findings of Nwanjo et al., 2007; Wali et al., 2013; Chen et al., 2002; Aquil et al., 2013 and Kamel et al., 2014, that showed a reduction in the antioxidant compounds in hypertensive subjects. The decrease in the antioxidant enzymes could be due to their inactivation as a result of a continuous exposure to hydrogen peroxide, hydrogen peroxynitrite (Redon et al., 2003) and other free radicals and also as a result of down regulation of their gene expression (Simic et al., 2006).

Altered glucose metabolism leads to an increased production of the reactive aldehyde, methylgloxal. Methlgloxal binds sulflydryl and amino group of proteins forming conjugates/advanced glycation end products (AGE's). This alters protein structure and function and can affect vascular calcium channels, enzymes and tissue proteins leading to increased oxidative stress. (Sudesh and Vicki, 2005). These alterations impair endothelial functions leading to an increase in intracellular free calcium peripheral vascular resistance as seen in hypertensive/kidney impairment. In chronic diabetic subjects, the autoxidation of glucose due to persistent hyperglycemia is the major cause for generating oxidative stress with concomitant depletion of the antioxidant compounds as seen in the findings of chugh et al., 1999 and Prechl et al., 1997.

Several reports have also shown reduction of the antioxidant compounds in sickle cell disease (Folake et al., 2008; Emokpae et al., 2010).

The different disease states are associated with different pathophysiological conditions with altered metabolism and oxidative stress and this could account for the lower levels of these antioxidant vitamins and enzymes.

\section{Conclusion}

The result of the study indicated that the levels of the enzymes, superoxide dismutase, glutathione peroxidase, catalase and the vitamins $\mathrm{A}, \mathrm{C}$, and $\mathrm{E}$ were significantly lower $(\mathrm{P}<0.05)$ in the subjects with altered metabolism than the values obtained for the control subjects. This reduction in the level of the antioxidant enzymes in relation to the level of the antioxidant vitamins showed a positive correlation at $95 \%$ confidence level. The reduction is as a result of increase in oxidation stress in these diseases that requires higher utilization of these antioxidants. Disclosure statement We hereby state categorically that there was no conflict of interest in the cause of this study

\section{Acknowledgments}

This is to acknowledge the sponsorship in part of this study by De-integrated Medical Diagnostic and Research Laboratories, Port Harcourt, Nigeria.

\section{References}

[1]. Aquil, A., Usha, S., Mohd, M.H., Najmul, I. and Imran, R. (2013). The role of Endogenous antioxidant enzymes and malondialdehyde in essential hypertension. Journal of Clinical Diagnostic Research 7(6): 987-990.

[2]. Azar, B., Hamid, N. and Mahmoud, R.K. (2014). Oxidative stress and hypertension. Possibility of hypertension therapy with antioxidants. Journal of India Academy of clinical Medicine 12(2): 122-127.

[3]. Baynes, J.W. and Thorpe, S.R. (1996). The role of oxidative stress in diabetic complications. Current Opinion Endocrinology 3: 227-284.

[4]. Chen, J., He, J., Hamm, L., Batuman, V. and Whelton, P.K. (2002). Serum antioxidant vitamins and blood pressure in United States. Population Hypertension 40(6): 810-816.

[5]. Chobanian, A.V., Bakris, G.L., Black, H.R., Cushman W.C., Green, L.A., Izzo, J.L. et al (2003). Seventh report of the joint National Committee on prevention, detection, evaluation and treatment of high blood pressure. Hypertension 42: $1206-1252$.

[6]. Chugh, S.N., Kakken, R., Kaira, S. and Sharma, A. (1999). An evaluation of oxidative stress In Diabetes mellitus during uncontrolled and controlled state and after vitamin E supplementation. Journal of the Association Physicians of India 47(4): 380208. 
[7]. Coyne, T. (2005). Antioxidant; American Journal of Clinical Nutrient 82: 3685-3698

[8]. Davies, K.Y. (1995). Oxidative stress. The paradox of aerobic life. Biochemical society symposium 61: 1-31.

[9]. Emokpae, A.M., Ojiefo, U.P. and Aisha, K.G. (2010). Antioxidant enzymes and acute phase proteins. Correlate with marker of lipid peroxide in adult Nigeria sickle cell disease patients. Iran Journal of Basic Sciences 13: 177-183.

[10]. Erika, S., Joseph, P., Janos, F. and Aniko, S. (1999). Alterations in enzymatic antioxidant defense in diabetes mellitus - a rational approach. Postgraduate Medical Journal 75: 13 - 17

[11]. Ezeiruaku, F.C. and Udenwoke, I.O. (2016). Evaluation of plasma glutathione peroxidase (GPX) enzyme in type 1 and type 2 chronic DM patients in Yenegoa, Bayelsa State, Nigeria. International Research on Medical Sciences 4(3): 50-54.

[12]. Foluke, F., Kayode, A., Johan, A. and Modupe, K. (2008). Antioxidant status in sickle cell disease patients in steady state. Journal of National Medical Association 100: 891-892.

[13]. Gingliano. D., Ceriello, A. And Paolisso, G. (1996). Oxidative stress and diabetic vascular complication. Diabetes Care 19: 257267

[14]. Huisman, J.H.J. (1981). Sickle cell anemia as a syndrome. A review of diagnostic features. American Journal of Haematology. 6: $173-177$

[15]. Kamal, K., Meena, V., Ankita, S., Poonani, K. and Rajesh, K.J. (2014). Oxidative stress and antioxidant enzyme levels in Hypertensive chronic kidney disease patients. International Journal of Biomedical and Advance Research 5(10): 351-359

[16]. Lamia, M.A., Mae'ad, K.H. and Jawad, K.M. (2015). Association of erythrocytes antioxidant enzymes and their co-factors with markers of oxidative stress in patients with sickle cell disease. Qatar Medical Journal 2: 14-32

[17]. Lenaz, G. (2001). The Mitochondrial production of reactive oxygen species; Mechanisms and implications in human pathology. IUBMB life 52 (5): 159-164

[18]. Manisha, T. (1999). Antioxidant and their role in M.Heart disease and cancer. Journal of the Diabetic Association of India 39(3): 69-73

[19]. Mujahid, B., Vibhor, S., Nishat, A., Ankush, G. and Jasim, M. (2011). Role of antioxidants in hypertension. Journal of Indian Academy of Clinical Medicine 12(2): 122-127.

[20]. Nur,E., Biemond. B.J., Otten.U.M., Brandjes, D.P. and Schnong, J.J. (2011). CURAMA Study Group, oxidative stress in sickle cell disease; Pathophysiology and potential implication for disease management. American Journal of Haematology 86(6): 484489

[21]. Nwanjo, H.U., Oze, G., Okafor, M.C, Nwasu, D. and Nwankpa, P. (2007). Oxidative stress and non enzymatic antioxidant status in hypertensive patients in Nigeria.

[22]. African Journal of Biotechnology 6: 168-1684.

[23]. Odievre, M.H., Verga, E., Silver-Pinto, A.C and Elion, J. (2011). Pathophysiologycal insight in sickle cell disease. Indian Journal of Medicine and Research 134(4): 532-537.

[24]. Oparil, S., Zaman, M.A. and Calhoun, D.A. (2003). Pathogenesis of hypertension. Annal international Medicine. 139: 761-776.

[25]. Peter, H., Scott, E.W. and Steven, A.T. (2001). Enzymes linked immune sorbent assay (ELISA). Current protocols in Molecular Biology II.

[26]. Prechl, T., Szaleczky, E., Pusztai, P., Kocsis, I., tulassay, Z. and Somogyl, A. (1987). Effect of clinical duration of diabetic mellitus on various antioxidants in blood. Medical Science Monitor 3: 167-170.

[27]. Redon, J., Oliva, M.R., Tormos, C., Giner, V., Chaves, J., Iradi, A. and Saez, G.T. (2003).

[28]. Antioxidant activities and oxidative stress by product in human hypertension.

[29]. Hypertension 41: 1096-111.

[30]. Rodrigo, R., Gonzalez, J. And Paoletto, F. (2011). The role of oxidative stress in the pathophsiology of hypertension. Hypertension Research 34: $431-440$.

[31]. Schiffrin, E., (2010). Antioxidants in hypertension and cardiovascular disease. Molecular intervention 10(6): $354-362$.

[32]. Sies, H. (1995) Strategies of antioxidant defense. European Journal of Biochemistry 415: 215-219

[33]. Sies, H. (1997). Oxidative stress. Oxidants and antioxidants. Experimental physiology 82(2): 291-295.

[34]. Simic, D.V., Mimic-oka, J., Pljesa-Ercegovac, M., Savic-Radojevic, A., Opacic, M Matic, D., et al (2006). By products of oxidative protein damage and antioxidant enzyme activities in plasma of patients with different degrees of essential hypertension. Journal of Human hypertension 20: 149 - 155

[35]. Sinha, N. and Dabla, P.K. (2015). Oxidative stress and antioxidants in hypertension-a current review. Current Hypertension Review 11 (2): 132-142.

[36]. Sudesh, V. and Vicki, G. (2005). Antioxidants in the treatment of hypertension. International Journal of Angiology 14(2): 60 73.Uotila, M., Ruosialti, E. and Engrall, E. (1981)

[37]. Enzymes linked immune assays. Journal of Immunological methods 42: 11-15. Wali, U., Yeldu, M.H. and Mohammed, Y. (2013)

[38]. Antioxidant vitamins status of hypertensive subjects in Sokoto Nigeria. Bayero Journal of pure and Applied Sciences 7 (1): $34-36$

[39]. Walter., P.B., Fung, E.M., Killibea, D.W., Jiang, Q., Hudes, M., Madlen, J., Evans, P., Vickinsky, E. and Harmata, P. (2006). Oxidative stress and inflammation in Iron-overloaded patients with bate-thalassaemia or sickle cell disease. British Journal of Haematology 135 (2): 254-263

[40]. West, I. (2000). Radical and oxidative stress in diabetes. Diabetic Medicine 17: 171-180.

[41]. World Health Organization (2011). Use of glycated haemoglobin (HbAic) in diagnosis of diabetes mellitus. Abbrevited Report of a WHO consultation. Geneva.

[42]. Wright, D., Reid, M. and Stenneth, R. (2014). Antioxidant intake in sickle cell disease and cancer. International Journal of Clinical Nutrition 2 (3): $53-59$

[43]. Yoshikawa, T., Toyokuni, S., Yamamoto, Y. and Naito, Y. (2000). Free radical in Chemistry, Biology and Medicine. London, UK: OICA International 580. 